\title{
Chronic Spontaneous Urticaria: Pathogenesis and Treatment Considerations
}

\author{
Allen P. Kaplan* \\ Department of Medicine, Division of Pulmonary and Critical Care Medicine, Allergy and Clinical Immunology, Medical University of South Carolina, Charleston, \\ SC, USA
}

This is an Open Access article distributed under the terms of the Creative Commons Attribution Non-Commercial License (http://creativecommons.org/licenses/by-nc/4.0/) which permits unrestricted non-commercial use, distribution, and reproduction in any medium, provided the original work is properly cited.

The treatment of chronic spontaneous urticaria begins with antihistamines; however, the dose required typically exceeds that recommended for allergic rhinitis. Second-generation, relatively non-sedating $H_{1}$-receptor blockers are typically employed up to 4 times a day. First-generation antihistamines, such as hydroxyzine or diphenhydramine (Atarax or Benadryl), were employed similarly in the past. Should high-dose antihistamines fail to control symptoms (at least $50 \%$ ), omalizumab at $300 \mathrm{mg} / \mathrm{month}$ is the next step. This is effective in $70 \%$ of antihistamine-refractory patients. $\mathrm{H}_{2}$-receptor blockers and leukotriene antagonists are no longer recommended; they add little and the literature does not support significant efficacy. For those patients who are unresponsive to both antihistamines and omalizumab, cyclosporine is recommended next. This is similarly effective in $65 \%$ $70 \%$ of patients; however, care is needed regarding possible side-effects on blood pressure and renal function. Corticosteroids should not be employed chronically due to cumulative toxicity that is dose and time dependent. Brief courses of steroid e.g., 3-10 days can be employed for severe exacerbations, but should be an infrequent occurrence. Finally, other agents, such as dapsone or sulfasalazine, can be tried for those patients unresponsive to antihistamines, omalizumab, and cyclosporine.

Key Words: Urticaria; omalizumab; antihistamines

\section{INTRODUCTION}

Urticaria that is present for greater than 6 weeks is arbitrarily considered to be "chronic" based on the observations that acute, self-limited episodes of urticaria tend to subside in 1-3 weeks, and that by assuming a cutoff at 6 weeks, the likelihood that some exogenous cause of the pathogenic process is very low and thus differs from causes of acute urticaria. ${ }^{1}$ Acute urticaria is typically caused by an identifiable agent such as an allergic reaction to a food or drug, or associated with viral illnesses as is often the case in children. Conversely, an exogenous cause for the chronic circumstance is virtually never found.

Urticaria lasting greater than 6 weeks is divided into 2 general groups; namely, inducible or spontaneous. ${ }^{2}$ Inducible urticarias are, perhaps, more accurately described as intermittent urticarias because the frequency is dependent on the particular stimulus. In this category are physical urticarias e.g., cold urticaria and dermatographism. ${ }^{3}$ Others include local heat urticaria, generalized heat urticaria (more commonly called cholinergic urticaria), solar urticaria, and aquagenic urticaria. One inducible physical urticaria that differs from all of these is delayed pressure urticaria. ${ }^{4}$ Here there is an interval of hours between the time of application of the stimulus and the beginning of the rash. The lesions are long-lasting i.e., 12-36 hours, there is an inflammatory reaction on skin biopsy, and it responds to corticosteroids, but not antihistamines. This is the reverse of all the other inducible urticarias listed which appear a few minutes after the stimulus, disappear within 30 minutes to 2 hours, have no cellular infiltrate on biopsy, and generally respond to antihistamines, but not corticosteroids. ${ }^{5}$

The second major category is chronic spontaneous urticaria (CSU). Lesions appear unpredictably, are present most days of the week, can occur on virtually any part of the body, are associated with angioedema (but not laryngeal edema) in $40 \%$ of patients, and respond to corticosteroids; however, the dose and duration required is too great to recommend. Their use for anything other than a brief course to ameliorate severe episodes is unnecessary. About half the patients respond (i.e., are im-

Correspondence to: Allen P. Kaplan, MD, Department of Medicine, Division of Pulmonary and Critical Care Medicine, Allergy and Clinical Immunology, Medical University of South Carolina, Charleston, 171 Ashley Avenue, Charleston, SC 29425, USA.

Tel: +1-843-729-0264; Fax: +1-843-722-1253; E-mail: kaplana@musc.edu Received: February 15, 2017; Revised: April 6, 2017; Accepted: April 8, 2017

- There are no financial or other issues that might lead to conflict of interest. 
proved significantly) to antihistamines and the remainder are resistant, regardless of dose.

\section{PATHOGENESIS OF CSU}

For an extensive discussion of our current knowledge and historical perspectives, review articles can be consulted..$^{5-7}$ I will present a summary of current concepts including some areas that remain controversial. Since there is no exogenous stimulus or "cause," neither foods, drugs, food additives, or other chemicals are relevant which is why routine food skin testing or radioallergosorbent test (RAST) is not recommended for evaluation. A pseudoallergen elimination diet ${ }^{8}$ remains in the "controversial" group and is not employed by this author. Since infectious processes are not the cause, routine dental X-rays, sinus films, stool cultures, or liver function tests are not recommended. An area of remaining controversy is testing for Helicobacter pylori, or antibiotic therapy to eliminate it, if found. This author considers any association to be spurious because a positive antibody test or even a positive examination of gastric contents is very common in the general population, and the proper double-blind studies needed to prove the point have never been done.

Given the aforementioned discussion, the evaluation of a typical patient with CSU with no other health issues would be a complete blood count (CBC), differential, erythrocyte sedimentation rate (ESR) and/or C-reactive protein (CRP), and little else. A prominent eosinophilia would suggest checking a stool sample for ova and parasites. A prominently elevated ESR/CRP is seen in autoimmune diseases, infections, malignancy, and any of these might be pursued if other symptoms or signs suggest further evaluation. ${ }^{2}$

There is an increased incidence of antithyroid antibodies in CSU-both immunoglobulin G (IgG) antiperoxidase and IgG antithyroglobulin ${ }^{9}$ with an incidence of about $25 \%{ }^{10} \mathrm{~A}$ subpopulation of such patients may have clinically significant Hashimoto's thyroiditis. ${ }^{11}$ This is the main autoimmune association of CSU, but most guidelines do not recommend obtaining a T3, T4, thyroid-stimulating hormone (TSH), or antithyroperoxidase as a routine. I prefer to include them and if hypothyroidism is present, it should be treated. On the other hand, patients with positive anti-bodies in the face of normal thyroid function should not receive thyroid supplementation. A very high incidence of immunoglobulin E (IgE) antithyroperioxidase has been reported in patients with $\mathrm{CSU}^{12}$ but controls utilizing patients with Hashimoto's thyroiditis, where IgG antithyroid antibodies approach $100 \%$, also have IgE antithyroid antibodies in the absence of urticaria. Thus IgE antibodies do not segregate with having urticaria. There is also a high incidence of positive antinuclear antibody (ANA)'s in patients with CSU, ${ }^{13}$ typically with a low titer and a speckled pattern. This has little significance which is why a routine ANA determination is not recom- mended unless hives are accompanied by symptoms of systemic lupus erythematosus (SLE) or other connective tissue disease. Further the incidence of finding a true vasculitis in patients undergoing skin biopsy is less than $1 \%$, thus skin biopsies are not recommended as a routine. The presence of petechiae, purpura, arthritis or severe arthralgia, elevated ESR/CRP, and lesions that last an unusually long time (36 hours or more) are circumstances in which a skin biopsy is reasonable. It is occasionally done when patients are refractory to treatment but this is rarely productive in the absence of the abnormalities listed. An exception would be when, on observing the rash, one is not sure whether it is or is not urticarial.

Among the possibilities for the etiology of CSU is that it is an autoimmune skin disease, or at least a subpopulation of patients could be considered as such. Depending on the authors, $35 \%-40 \%$ of patients have an IgG antibody to the $\alpha$ subunit of the high affinity IgE receptor (IgG anti-FceRI $\alpha)^{14,15}$ while an additional 5\%-10\% have IgG anti-IgE..$^{16,17}$ These are functional and can be shown to induce histamine release from blood basophils or cutaneous mast cells. ${ }^{18}$ Basophil activation is augmented by complement, ${ }^{10}$ which appears due to the formation of C5a. ${ }^{19}$ While a small percentage of normal subjects have such antibodies, ${ }^{20,21}$ and SLE patients may have a positive antibody assay in the absence of urticaria, ${ }^{22}$ the association with urticaria far exceeds these ${ }^{20}$ While such a determination (for example the Chronic Urticaria [CU] Index) is available commercially, it is considered to be a research tool and guidelines do not support its determination for routine evaluation. Even though positive tests do not dictate therapy, I typically include IgG antiFceRI $\alpha$ and antithyroid antibodies for interest regarding the possibility of an autoimmune etiology, or at minimum, a striking association with autoimmunity. Nevertheless, treatment is not dependent on the result.

Saini and associates ${ }^{23-25}$ have made novel observations regarding abnormal basophil numbers and function in CSU. In general, patients have basopenia which might represent migration of basophils to the skin during urticarial episodes. Basopenia reverses when urticaria remits or is successfully treated. ${ }^{25}$ In addition, the basophils of a sizeable subpopulation of patients (roughly half) are hyporesponsive when stimulated through the IgE receptor. ${ }^{23}$ Thus stimulation of basophils of such patients with an anti-IgE made in rabbits causes significantly less histamine release than is obtained employing basophils from normal controls. This functional abnormality appears to reverse (i.e., the cells paradoxically release more histamine) when patients improve/remit. ${ }^{25}$ The abnormality has been attributed to increased levels of phosphatases (e.g., SHP-1 is Src homology tyrosine phosphatase-1) in patients' basophils thereby dephosphorylating factors whose phosphorylated forms are important for cell secretion..$^{23}$ Thus far one cannot distinguish whether this abnormality is a key to the cause of the urticaria or is secondary to other pathogenic mechanisms that are operative. 
Table 1. Immunologic associations identified in patients with CSU

1. $\lg \mathrm{G}$ anti-FcER| $\alpha$ in $30 \%-40 \%$

2. $\lg \mathrm{G}$ antibody to $\lg \mathrm{E} 5 \%-10 \%$

3. Increased incidence of Hashimoto's thyroiditis

4. $\lg \mathrm{G}$ antibody to thyroid antigens (antithyroglobulin and antiperoxidase) $25 \%$

5. $\lg$ E antibodies to thyroperoxidase

6. Positive ANA-speckled pattern 30\%

7. Expression to Th-2-initiating cytokines in skin biopsies including TSLP, IL-25, and IL-33 30

CSU, chronic spontaneous urticaria; IgG, immunoglobulin G; IgE, immunoglobulin $E_{;} \lg G$ anti-FceRi $\alpha$, IgG antibody to the $\alpha$ subunit of the high affinity $\lg E$ receptor; ANA, antinuclear antibody; TSLP, thymic stromal Iymphopoietin; IL, interleukin.

Additional abnormalities noted are high levels of metalloproteinases ${ }^{26}$ in the plasma of patients with CSU as well as increased fibrin split products and prothrombin fragment $1-2^{27,28}$ suggesting activation of the coagulation cascade and fibrinolysis even though there is no clinical abnormality in hemostasis or thrombosis in this disorder. A summary of major immunologic associations observed in patients with CSU is given in Table 1.

\section{TREATMENT OF CSU}

A new guideline has been approved as of December 2016 and endorsed thus far by the European Academy of Allergy and Clinical Immunology (EAACI) and the World Allergy Organization (WAO), but has not yet been published. The prior iteration is now out-of-date ${ }^{2}$ and many changes were made. I will refer to an earlier publication entitled: Therapy of chronic urticaria: a simple, modern approach ${ }^{29}$ which, like the new guideline, emphasizes the utility of omalizumab and cyclosporine for antihistamine-resistant patients (Table 2).

Antihistamines remain the initial approach to therapy and approximately $50 \%$ of patients respond sufficiently to require no further treatment. Yet one must bear in mind that at last half such patients are unresponsive so that the statement that "most patients with CSU respond well to antihistamines" might be false. Nevertheless, second-generation antihistamines are effective and carry fewer side-effects, such as sedation and mucosal dryness, compared to their first-generation counterparts. These antihistamines were first approved for allergic rhinitis where 1 tablet/day usually suffices, but that is often not the case for urticaria. Thus a rapid increase to 4 tablets/day is recommended..$^{30}$ Also, this is true for most inducible urticarias ${ }^{31}$ as well as CSU. My preference is to increase to 4 tablets/day quickly and if it works, decrease the dose after a few weeks rather than increasing one pill at a time. If 4 tablets/day is not satisfactory, the patient is likely to be in the antihistamine-resistant group.

It is clear that the most effective agent, with best side-effect
Table 2. Approaches to consider when antihistamines fail

\begin{tabular}{ccc}
\hline A & B & C \\
\hline Omalizumab & Dapsone & Corticosteroid \\
Cyclosporine & Hydroxychloroquine & H2 receptor antagonists \\
& Sulfasalazine & Leukotriene antagonists \\
& Colchicine & \\
& Methotrexate & \\
& Intravenous gamma globulin & \\
& Plasmapheresis &
\end{tabular}

A: recommended; if " $A$ " fails, consider B; C: not recommended.

Failure of antihistamins, omalizumab, and cyclosporine may leave no option other than those listing as "B" or use of low-dose chronic corticosteroid with the provisos described in the text.

profile for CSU, is Xolair ${ }^{\circledR}$ (omalizumab; Novartis Pharmaceuticals Corp., East Hanover, NJ, USA). A proof-of-concept study demonstrated striking efficacy in severe, autoimmune-associated $\mathrm{CSU}^{32}$; it was placebo controlled and single-blind. This was followed by a dose-escalating phase 2 trial $^{33}$ and a study of patients with IgE antiperoxidase antibodies ${ }^{34}$ each of which demonstrated efficacy. These were placebo-controlled and doubleblind. Finally, 3 phase 3 trials totaling over 900 patients revealed a response rate of $60 \%-70 \%$, a complete response rate of about $40 \%$, and effective doses of 150 or $300 \mathrm{mg}$ per injection without regard to body weight or IgE level. ${ }^{35-37}$ It was clear that the 300 $\mathrm{mg}$ dose/month was more effective than the $150 \mathrm{mg}$ dose, but that after 6 months, most patients reverted to the placebo level. ${ }^{36}$ Thus 6 months of treatment did not affect the natural course of the disease but suppressed the symptoms. Pruritus was proportionately reduced as the number of hives diminished. While omalizumab carries a $2 \%-3 \%$ incidence of anaphylaxis when employed for asthma, anaphylaxis was not observed in the urticaria trials. This should be the drug of choice for antihistamine-resistant cases since failure of antihistamines was a criterion for most of the aforementioned studies and one $^{36}$ consisted of patients who failed H1-antagonists, H2-antagonists, and leukotriene antagonists.

The next issue is what to do for antihistamine-resistant patients who fail to respond to omalizumab. This subpopulation of patients represents about $15 \%-20 \%$ of the total. The most effective of the remaining possibilities is cyclosporine; a conclusion which emerged from double-blind, placebo-controlled studies $^{38,39}$ plus subsequent reports ${ }^{40}$ and personal observations. Like omalizumab, the response rate is $60 \%-70 \%$, but one has to monitor patients carefully because it does have potential toxicity. A typical dose for an adult is $200 \mathrm{mg}$ /day with monitoring of blood pressure and renal function every 6 weeks assuming they are normal when the medication is instituted. It is preferable to a host of alternatives, to be addressed below, because its efficacy is far greater. Employment of agents whose efficacy is questionable or minimal in severe patients because they have 
Table 3. Therapy of CSU

Step I Non-sedating, second or third generation antihistamines taken 4 times a day. Decrease the dose as tolerated once control of symptoms is attained.

If response inadequate,

Step II Omalizumab 300 mg monthly

If no response after 3-4 injections,

Step III Cyclosporine 200-300 mg/day

Step IV Drugs to consider if steps I-III fail are dapsone, methotrexate, sulfasalazine, hydroxychloroquine, intravenous gamma globulin and plasmapheresis

Dose of cetirizine, loratidine, desloratidine, or xyzal corresponding to hydroxyzine or diphenhydramine at $50 \mathrm{mg}$ q.i.d. is 6 tablets/day.

Patient response to step I:45\%; step II:65\% of the remainder(predicted response rate of steps I plus II is 80\%);patients response to step III: $65 \%$ of the remainder(predicted total response rate for steps I, II, and III is 92\%)

little or no toxicity makes no sense. Prior guidelines have stated "complete control" as a goal and this may not be attainable when one looks beyond antihistamines, omalizumab, and cyclosporine. The percent success rate i.e., significant (but not complete) improvement with these 3 agents has been estimated to be $93 \%{ }^{29}$ (Table 3 ). It is predicated on the fact that a lack of response to any one agent has no implication for responsiveness to another.

I will briefly address the reliability of other therapeutic possibilities. $\mathrm{H}_{2}$-antagonists have never been shown to improve urticaria beyond that achievable with $\mathrm{H}_{1}$-antagonists. Their use was based on studies showing that a histamine-induced wheal and flare reaction in the skin can be blocked further by addition of an $\mathrm{H}_{2}$-antagonist once $\mathrm{H}_{1}$-receptor blockade has been achieved. ${ }^{41}$ This does not translate into clinical efficacy in CSU and $\mathrm{H}_{2}$-antagonists were eliminated in the last EAACI guideline ${ }^{2}$ but retained in American guidelines. ${ }^{1}$

Leukotriene antagonists are also employed as adjunctive agents when $\mathrm{H}_{1}$-receptor blockade has been achieved. There is literature pro $^{42}$ and con, ${ }^{43}$ but no large-scale double-blind placebo-controlled study has been done. My personal experience is that patient's refractory to antihistamines will not respond to leucotriene antagonists, so I am opposed to their general use as treatment of CSU. They might have some role in patients whose urticaria is exacerbated by aspirin ${ }^{44}$ or other non-steroidal antiinflammatory agents although eliminating them, if possible, is a better approach. Acetaminophen can be safely substituted.

A more promising possibility is perhaps dapsone. While there are many case reports claiming success, proper double-blind placebo-controlled trials are limited. Perhaps the best and most recent trial demonstrated a response rate of $30 \%-40 \%$ for dapsone ${ }^{45}$ with a placebo response of $10 \%$. While the success rate is far lower that of cyclosporine or omalizumab, a conundrum is the $10 \%$ placebo response when we know the placebo response rate in CSU is about $25 \%-30 \%{ }^{35-37}$ Thus the result is question- able and the increment from the usual response rate is small. In fact, the most recent publication suggests that the success rate of the pseudoallergen-free $\operatorname{diet}^{46}$ approximates that of the placebo rate.

Other agents considered in earlier guidelines include sulfasalazine, methotrexate, and plaquanil. The study examining sulfasalazine was not properly controlled ${ }^{47}$ and it seems unlikely that a sulfa drug combined with an aspirin derivative (salicylate) is likely to help urticaria. Methotrexate has never really been studied; however, the few times I have tried it, there was no effect. Plaquenil ${ }^{\mathbb{B}}$ (hydroxychloroquine; Concordia Pharmaceuticals Inc., Oakville, Canada) is particularly effective for the hypocomplementemic urticarial vasculitis syndrome, ${ }^{48}$ a rare type of cutaneous vasculitis, but its efficacy for CSU is largely anecdotal. $^{49}$

Corticosteroids are effective for CSU, but its use should be limited to short courses for acute amelioration of severe urticaria/angioedema episodes and should not be employed for chronic use because the side effects outweigh the efficacy. When employed in the past, the doses were too high and sustained for too long. Isolated angioedema can be treated with 40 mg prednisone on 2 successive days and then discontinue it without any taper. A severe urticarial episode with or without angioedema can be treated with $40 \mathrm{mg} /$ day for 3 days; then decrease by $5 \mathrm{mg}$ each day for a total of 10 days. That is sufficient time for the approach outlined above to be instituted.

\section{REFERENCES}

1. Bernstein JA, Lang DM, Khan DA, Craig T, Dreyfus D, Hsieh F, et al. The diagnosis and management of acute and chronic urticaria: 2014 update. J Allergy Clin Immunol 2014;133:1270-7.

2. Zuberbier T, Aberer W, Asero R, Bindslev-Jensen C, Brzoza Z, Canonica GW, et al. The EAACI/GA(2) LEN/EDF/WAO Guideline for the definition, classification, diagnosis, and management of urticaria: the 2013 revision and update. Allergy 2014;69:868-87.

3. Abajian M, Schoepke N, Altrichter S, Zuberbier T, Maurer M. Physical urticarias and cholinergic urticaria. Immunol Allergy Clin North Am 2014;34:73-88.

4. Mekori YA, Dobozin BS, Schocket AL, Kohler PF, Clark RA. Delayed pressure urticaria histologically resembles cutaneous latephase reactions. Arch Dermatol 1988;124:230-5.

5. Kaplan AP, Greaves M. Pathogenesis of chronic urticaria. Clin Exp Allergy 2009;39:777-87.

6. Kaplan AP. Chronic urticaria: pathogenesis and treatment. J Allergy Clin Immunol 2004;114:465-74.

7. Saini SS. Chronic spontaneous urticaria: etiology and pathogenesis. Immunol Allergy Clin North Am 2014;34:33-52.

8. Zuberbier T, Pfrommer C, Specht K, Vieths S, Bastl-Borrmann R, Worm M, et al. Aromatic components of food as novel eliciting factors of pseudoallergic reactions in chronic urticaria. J Allergy Clin Immunol 2002;109:343-8.

9. Leznoff A, Sussman GL. Syndrome of idiopathic chronic urticaria and angioedema with thyroid autoimmunity: a study of 90 patients. J Allergy Clin Immunol 1989;84:66-71. 
10. Kikuchi Y, Fann T, Kaplan AP. Antithyroid antibodies in chronic urticaria and angioedema. J Allergy Clin Immunol 2003;112:218.

11. Sugiyama A, Nishie H, Takeuchi S, Yoshinari M, Furue M. Hashimoto's disease is a frequent comorbidity and an exacerbating factor of chronic spontaneous urticaria. Allergol Immunopathol (Madr) 2015;43:249-53.

12. Guo J, Rapoport B, McLachlan SM. Thyroid peroxidase autoantibodies of IgE class in thyroid autoimmunity. Clin Immunol Immunopathol 1997;82:157-62.

13. Viswanathan RK, Biagtan MJ, Mathur SK. The role of autoimmune testing in chronic idiopathic urticaria. Ann Allergy Asthma Immunol 2012;108:337-341.e1.

14. Hide M, Francis DM, Grattan CE, Hakimi J, Kochan JP, Greaves MW. Autoantibodies against the high-affinity IgE receptor as a cause of histamine release in chronic urticaria. N Engl J Med 1993; 328:1599-604.

15. Kikuchi Y, Kaplan AP. Mechanisms of autoimmune activation of basophils in chronic urticaria. J Allergy Clin Immunol 2001;107: 1056-62.

16. Gruber BL, Baeza ML, Marchese MJ, Agnello V, Kaplan AP. Prevalence and functional role of anti-IgE autoantibodies in urticarial syndromes. J Invest Dermatol 1988;90:213-7.

17. Grattan CE, Francis DM, Hide M, Greaves MW. Detection of circulating histamine releasing autoantibodies with functional properties of anti-IgE in chronic urticaria. Clin Exp Allergy 1991;21:695704.

18. Niimi N, Francis DM, Kermani F, O'Donnell BF, Hide M, KobzaBlack A, et al. Dermal mast cell activation by autoantibodies against the high affinity IgE receptor in chronic urticaria. J Invest Dermatol 1996;106:1001-6.

19. Kikuchi Y, Kaplan AP. A role for C5a in augmenting IgG-dependent histamine release from basophils in chronic urticaria. J Allergy Clin Immunol 2002;109:114-8.

20. Kaplan AP, Joseph K. Basophil secretion in chronic urticaria: autoantibody-dependent or not? J Allergy Clin Immunol 2007;120:72930.

21. Du Toit G, Prescott R, Lawrence P, Johar A, Brown G, Weinberg EG, et al. Autoantibodies to the high-affinity IgE receptor in children with chronic urticaria. Ann Allergy Asthma Immunol 2006;96:3414.

22. Cho CB, Stutes SA, Altrich ML, Ardoin SP, Phillips G, Ogbogu PU. Autoantibodies in chronic idiopathic urticaria and nonurticarial systemic autoimmune disorders. Ann Allergy Asthma Immunol 2013;110:29-33.

23. Vonakis BM, Vasagar K, Gibbons SP Jr, Gober L, Sterba PM, Chang $\mathrm{H}$, et al. Basophil FcepsilonRI histamine release parallels expression of Src-homology 2-containing inositol phosphatases in chronic idiopathic urticaria. J Allergy Clin Immunol 2007;119:441-8.

24. Eckman JA, Hamilton RG, Gober LM, Sterba PM, Saini SS. Basophil phenotypes in chronic idiopathic urticaria in relation to disease activity and autoantibodies. J Invest Dermatol 2008;128:195663.

25. Oliver ET, Sterba PM, Saini SS. Interval shifts in basophil measures correlate with disease activity in chronic spontaneous urticaria. Allergy 2015;70:601-3.

26. Kessel A, Bishara R, Amital A, Bamberger E, Sabo E, Grushko G, et al. Increased plasma levels of matrix metalloproteinase-9 are associated with the severity of chronic urticaria. Clin Exp Allergy 2005; 35:221-5.
27. Tedeschi A, Kolkhir P, Asero R, Pogorelov D, Olisova O, Kochergin $\mathrm{N}$, et al. Chronic urticaria and coagulation: pathophysiological and clinical aspects. Allergy 2014;69:683-91.

28. Fujii K, Usuki A, Kan-No Y, Ohgou N. Elevation of circulating thrombin-antithrombin III complex and fibrin degradation products in urticaria: a laboratory finding unrelated to intravascular coagulopathy. J Dermatol 2008;35:308-10.

29. Kaplan AP. Therapy of chronic urticaria: a simple, modern approach. Ann Allergy Asthma Immunol 2014;112:419-25.

30. Staevska M, Popov TA, Kralimarkova T, Lazarova C, Kraeva S, Popova $\mathrm{D}$, et al. The effectiveness of levocetirizine and desloratadine in up to 4 times conventional doses in difficult-to-treat urticaria. J Allergy Clin Immunol 2010;125:676-82.

31. Siebenhaar F, Degener F, Zuberbier T, Martus P, Maurer M. Highdose desloratadine decreases wheal volume and improves cold provocation thresholds compared with standard-dose treatment in patients with acquired cold urticaria: a randomized, placebocontrolled, crossover study. J Allergy Clin Immunol 2009;123:6729.

32. Kaplan AP, Joseph K, Maykut RJ, Geba GP, Zeldin RK. Treatment of chronic autoimmune urticaria with omalizumab. J Allergy Clin Immunol 2008;122:569-73.

33. Saini S, Rosen KE, Hsieh HJ, Wong DA, Conner E, Kaplan A, et al. A randomized, placebo-controlled, dose-ranging study of singledose omalizumab in patients with $\mathrm{H} 1$-antihistamine-refractory chronic idiopathic urticaria. J Allergy Clin Immunol 2011;128:567573.el.

34. Maurer M, Altrichter S, Bieber T, Biedermann T, Bräutigam M, Seyfried S, et al. Efficacy and safety of omalizumab in patients with chronic urticaria who exhibit IgE against thyroperoxidase. J Allergy Clin Immunol 2011;128:202-209.e5.

35. Maurer M, Rosén K, Hsieh HJ, Saini S, Grattan C, Gimenéz-Arnau A, et al. Omalizumab for the treatment of chronic idiopathic or spontaneous urticaria. N Engl J Med 2013;368:924-35.

36. Kaplan A, Ledford D, Ashby M, Canvin J, Zazzali JL, Conner E, et al. Omalizumab in patients with symptomatic chronic idiopathic/ spontaneous urticaria despite standard combination therapy. J Allergy Clin Immunol 2013;132:101-9.

37. Saini SS, Bindslev-Jensen C, Maurer M, Grob JJ, Bülbül Baskan E, Bradley MS, et al. Efficacy and safety of omalizumab in patients with chronic idiopathic/spontaneous urticaria who remain symptomatic on $\mathrm{H1}$ antihistamines: a randomized, placebo-controlled study. J Invest Dermatol 2015;135:67-75.

38. Grattan CE, O'Donnell BF, Francis DM, Niimi N, Barlow RJ, Seed PT, et al. Randomized double-blind study of cyclosporin in chronic 'idiopathic' urticaria. Br J Dermatol 2000;143:365-72.

39. Vena G, Cassano N, Colombo D, Peruzzi E, Pigatto P; Neo-I-30 Study Group. Cyclosporine in chronic idiopathic urticaria: a double-blind, randomized, placebo-controlled trial. J Am Acad Dermatol 2006;55:705-9.

40. Kessel A, Toubi E. Cyclosporine-A in severe chronic urticaria: the option for long-term therapy. Allergy 2010;65:1478-82.

41. Harvey RP, Schocket AL. The effect of H1 and H2 blockade on cutaneous histamine response in man. J Allergy Clin Immunol 1980; 65:136-9.

42. Erbagci Z. The leukotriene receptor antagonist montelukast in the treatment of chronic idiopathic urticaria: a single-blind, placebocontrolled, crossover clinical study. J Allergy Clin Immunol 2002; 110:484-8. 
43. Di Lorenzo G, Pacor ML, Mansueto P, Esposito Pellitteri M, Lo Bianco C, Ditta V, et al. Randomized placebo-controlled trial comparing desloratadine and montelukast in monotherapy and desloratadine plus montelukast in combined therapy for chronic idiopathic urticaria. J Allergy Clin Immunol 2004;114:619-25.

44. Pacor ML, Di Lorenzo G, Corrocher R. Efficacy of leukotriene receptor antagonist in chronic urticaria. A double-blind, placebocontrolled comparison of treatment with montelukast and cetirizine in patients with chronic urticaria with intolerance to food additive and/or acetylsalicylic acid. Clin Exp Allergy 2001;31:1607-14.

45. Morgan M, Cooke A, Rogers L, Adams-Huet B, Khan DA. Doubleblind placebo-controlled trial of dapsone in antihistamine refractory chronic idiopathic urticaria. J Allergy Clin Immunol Pract 2014;2:601-6.

46. Magerl M, Pisarevskaja D, Scheufele R, Zuberbier T, Maurer M. Effects of a pseudoallergen-free diet on chronic spontaneous urticar- ia: a prospective trial. Allergy 2010;65:78-83.

47. McGirt LY, Vasagar K, Gober LM, Saini SS, Beck LA. Successful treatment of recalcitrant chronic idiopathic urticaria with sulfasalazine. Arch Dermatol 2006;142:1337-42.

48. Lopez LR, Davis KC, Kohler PF, Schocket AL. The hypocomplementemic urticarial-vasculitis syndrome: therapeutic response to hydroxychloroquine. J Allergy Clin Immunol 1984;73:600-3.

49. Reeves GE, Boyle MJ, Bonfield J, Dobson P, Loewenthal M. Impact of hydroxychloroquine therapy on chronic urticaria: chronic autoimmune urticaria study and evaluation. Intern Med J 2004;34:1826.

50. Kay AB, Clark P, Maurer M, Ying S. Elevations in T-helper-2-initiating cytokines (interleukin-33, interleukin-25 and thymic stromal lymphopoietin) in lesional skin from chronic spontaneous ('idiopathic') urticaria. Br J Dermatol 2015;172:1294-302. 